\title{
Arranjos familiares e desempenho escolar de alunos do 5으 e 9으 anos no Brasil em 2015
}

\author{
Larissa de Eleterio Lima* \\ Angelita Alves de Carvalho** \\ Denise Britz do Nascimento Silva ${ }^{\star \star \star}$
}

Os arranjos familiares têm se transformado a partir de diversos processos dinâmicos, como a redução da fecundidade, a emancipação da mulher e sua consequente inserção no mercado de trabalho, o aumento do número de divórcios e a ampliação da expectativa de vida. Essas transformações levaram a uma diminuição do tamanho das famílias e diversificação de sua composição. Diante do surgimento de novas estruturas familiares decorrentes da dinâmica social, este estudo analisa a relação dos arranjos familiares com o desempenho escolar dos alunos do 5 ㅇ e 9ํao anos de escolas públicas no Brasil em 2015, a partir dos dados da Prova Brasil. A nota de matemática foi utilizada como medida de desempenho e os efeitos da família foram avaliados a partir da modelagem hierárquica dos dados. Os resultados demonstram pouco efeito dos arranjos familiares sobre a proficiência média em matemática, evidenciando que outros elementos e mediadores relacionados aos resultados escolares, tais como status socioeconômico, trajetória do aluno, hábitos escolares individuais e ambiente da escola, apresentam maior relação com o desempenho escolar do que a composição do arranjo por si só.

Palavras-chave: Arranjos familiares. Desempenho escolar. Modelos hierárquicos.

\footnotetext{
* Escola Nacional de Ciências Estatísticas (Ence), Instituto Brasileiro de Geografia e Estatística (IBGE), Rio de Janeiro-RJ, Brasil (lelima@id.uff.br; https://orcid.org/0000-0002-2568-4205).

** Escola Nacional de Ciências Estatísticas (Ence), Instituto Brasileiro de Geografia e Estatística (IBGE), Rio de Janeiro-RJ, Brasil (angelita.carvalho@ibge.gov.br; https://orcid.org/0000-0002-9342-4181).

*** Escola Nacional de Ciências Estatísticas (Ence), Instituto Brasileiro de Geografia e Estatística (IBGE), Rio de Janeiro-RJ, Brasil (denise.silva@ibge.gov.br; https://orcid.org/0000-0002-5514-7558).
} 


\section{Introdução}

O estudo da dinâmica das transformações nos arranjos familiares considera duas principais características nos estudos da demografia: o seu tamanho e sua composição. 0 primeiro envolve basicamente o número de membros existentes na família e o segundo refere-se ao arranjo/relação desses membros que compõem a família.

Segundo o relatório World family map ${ }^{1}$ (CHILD TRENDS; SOCIAL TRENDS INSTITUTE, 2015), mudanças demográficas importantes, como redução da fecundidade, envelhecimento e aumento dos divórcios, têm afetado essas duas dimensões familiares, em que se observam diminuição do tamanho das famílias e maior heterogeneidade na sua composição, abarcando formas de arranjos que anteriormente eram percebidas como raras e marginais. Essa diversificação dos arranjos familiares pode ser verificada no aumento das famílias de dupla renda (em que ambos os cônjuges exercem atividade remunerada), das famílias com casais na fase do "ninho vazio", compostas por cônjuges mais idosos, de casais de mesmo sexo e de famílias reconstituídas, ${ }^{2}$ nas quais, a partir do crescimento do número de divórcios e recasamentos, as crianças passam a conviver com madrastas e padrastos (THERBORN, 2006).

Tais mudanças na estrutura familiar demandaram discussões a respeito dos impactos dessas transformações no âmbito emocional e no aprendizado das crianças, pois os arranjos familiares nos quais as crianças estão inseridas são centrais para o seu bem-estar. Estudos que investigaram os efeitos da heterogeneidade da composição da família, em específico as dissoluções familiares e a formação de famílias reconstituídas, encontraram evidências de efeitos físicos e emocionais para as pessoas envolvidas, em especial as crianças (AMATO, 2000; MCLANAHAN, 2004; MCLANAHAN; TACH; SCHNEIDER, 2013). Amato (2000) apresentou um modelo cujos resultados apontam que a dissolução do casamento criaria considerável turbulência na vida familiar, de forma que, dependendo de como os indivíduos envolvidos lidassem com esses conflitos, alguns se beneficiariam, rompendo com relações violentas e abusivas, mas outros poderiam experimentar decréscimos temporários no bem-estar, e ainda outros seriam impactados de forma negativa e persistente.

Especificamente na relação entre os arranjos familiares e o desempenho escolar de crianças, de modo geral, os estudos indicam uma relação negativa do divórcio e os novos arranjos familiares sobre o desempenho educacional dos filhos tanto internacionalmente (MCLANAHAM, 2004; MCLANAHAN; TACH; SCHNEIDER, 2013; CHILD TRENDS; SOCIAL TRENDS INSTITUTE, 2015; WOESSMANN, 2015) quanto para o Brasil (TOMÁS; WAJNMAN; CARVALHO, 2014; MARTINS; TEIXEIRA, 2016). Tomás, Wajnman e Carvalho (2014), de

\footnotetext{
${ }_{1}$ Pesquisa que se propõe a estudar o cotidiano de crianças e adolescentes de forma que seus resultados sirvam de apoio à decisão de gestores públicos. Disponível em: https://www.childtrends.org/publications/world-family-map-2015-mappingfamily-change-and-child-well-being-outcomes. Acesso em: 20 set. 2019.

${ }^{2}$ Trata-se de núcleos constituídos depois da separação ou morte de um dos cônjuges, quando os indivíduos separados, divorciados ou viúvos iniciam uma nova união, formando assim casais que podem conviver com filhos de uniões anteriores e com aqueles da união atual (SABOIA; COBO; MATOS, 2012).
} 
forma sintética e citando outros autores, indicam que existiriam três níveis de influências do divórcio sobre a vida das crianças: o primeiro seria um "efeito indireto da estrutura familiar, devido à perda de renda e mobilidade ou falta de envolvimento do pai ou falta de tempo gasto com os pais ou empregos e posições ocupacionais em desvantagem para as mulheres". O segundo seria um "efeito de seleção e endogeineidade, em que as crianças teriam problemas mesmo antes da interrupção". E o terceiro seria "o efeito família per se, como estresse e motivações dos pais para investir nos filhos".

Em paralelo, cada vez mais, tem sido discutidas a existência e a importância de outros fatores que também podem influenciar diretamente o desempenho escolar da criança, para além da estrutura da família: as condições socioeconômica e familiar - analisadas por meio de indicadores como escolaridade e hábitos de leitura dos pais, renda familiar, número de moradores no domicílio, quantidade de crianças na residência, convívio com outra família no mesmo domicílio, bem como fatores relacionados à convivência familiar, como brigas e discussões, instabilidade financeira, problemas de saúde por parte de algum dos pais. Esse debate traz luz para a multidimensionalidade da avaliação do desempenho escolar, isto é, reconhecendo a insuficiência do arranjo familiar para justificar um desempenho desigual, a condição socioeconômica acaba aprofundando a desigualdade na educação e o arranjo familiar constitui-se mais como uma variável que caracteriza os que estão em condição desigual do que um determinante por si só (MCLANAHAN; PERCHESKI, 2008; RIANI; RIOSNETO, 2008; BELLER, 2009; ALVES et al., 2013; CHILD TRENDS; SOCIAL TRENDS INSTITUTE, 2015; WOESSMANN, 2015; MOREIRA; JACINTO, 201; BASSETTO, 2019).

Seguindo a perspectiva multifatorial para a avaliação do efeito dos arranjos familiares sobre a vida escolar dos alunos, faz-se necessário incluir as variáveis individuais do aluno, como a sua trajetória e sua condição familiar, assim como o contexto escolar em que o mesmo está inserido (RESENDE et al., 2011; MEDEIROS; OLIVEIRA, 2014).

Existe no Brasil literatura relativamente recente sobre a associação entre desempenho escolar e arranjos familiares (MENEZES-FILHO, 2007; MARTELETO; DE SOUZA, 2012; ALVES et al, 2013; PALERMO; SILVA; NOVELLINO, 2014; TOMÁS; WAJNMAN; CARVALHO, 2014; LIMA; DOS SANTOS, 2014; MARTINS; TEIXEIRA, 2016; MOREIRA; JACINTO, 2017). Estes estudos ressaltam, entre os diversos determinantes do desempenho, a importância de considerar as características dos arranjos familiares das crianças e investigar seus efeitos. Contudo, o debate sobre a relação entre os arranjos familiares e o desempenho escolar, dada sua amplitude, ainda requer atenção no âmbito da realidade brasileira. Assim, o presente estudo se destaca por privilegiar a análise dos efeitos dos diferentes tipos de arranjos familiares sobre a proficiência em matemática controlando pelas variáveis de condição familiar e trajetória escolar das crianças e, adicionalmente, pelas variáveis do ambiente escolar via mensuração de modelos hierárquicos.

A partir dessa apresentação questiona-se: qual a relação entre os diferentes tipos de arranjos familiares e o desempenho escolar das crianças no Brasil ao se controlarem os efeitos do ambiente escolar? Existem diferenciais nessa relação de acordo com a série 
escolar da criança e com características da interação da família com a vida escolar dos alunos (se são estimulados a ler ou a fazer as tarefas de casa e se os pais conversam sobre o cotidiano escolar)? Quais fatores, dentre os associados à escolaridade dos pais, aos hábitos culturais familiares e à estrutura familiar, exercem maior influência sobre o desempenho escolar dos alunos? Quais outros fatores (variáveis de contexto e da escola) podem estar relacionados com o desempenho dos alunos?

Assim, o presente trabalho tem como objetivo analisar a relação entre arranjos familiares e o desempenho em matemática de crianças do 5ำ e 9ํa anos na Prova Brasil $2015 .{ }^{3}$ Procurou-se considerar para esse fim características das famílias, tais como escolaridade dos pais e estrato socioeconômico, uso do tempo livre das crianças e histórico escolar, além dos hábitos escolares e familiares. Também foram incluídas as características da escola, tais como região, localidade e tipo de administração, taxa de participação da escola na Prova Brasil e número de alunos presentes, no intuito de captar quaisquer diferenças que apontassem, para além do arranjo familiar, outros fatores relevantes já reconhecidos pela literatura de avaliação educacional.

\section{Arranjos familiares e o desempenho escolar}

Para analisar a relação entre os diferentes arranjos familiares e os resultados educacionais das crianças, muitos estudos têm sido conduzidos considerando diferentes séries escolares e diversas formas de avaliação do desempenho. A literatura internacional utiliza comumente variáveis relacionadas à conclusão da educação básica e continuidade no ensino superior para avaliar o impacto da família sobre a progressão escolar e a evasão.

Procurando identificar o motivo pelo qual o arranjo tinha influência sobre as chances de evasão, Beller (2009) observou que em famílias monoparentais o acompanhamento nos estudos é menos cuidadoso. Com isso, a criança não se sentia estimulada a estudar e teria mais chances de abandonar a escola antes de completar a educação básica.

De forma semelhante Garneau (2012), analisando os resultados de adolescentes norte-americanos a partir de um estudo longitudinal, concluiu que as crianças que viviam em famílias diferentes daquela composta por pai e mãe tinham menos chances de completarem o ensino médio se comparadas àquelas que viviam em famílias biparentais. Quando consideradas as famílias monoparentais, crianças que viviam apenas com a mãe tinham resultados escolares melhores do que aquelas que residiam apenas com o pai ou em famílias reconstituídas por madrasta/padrasto. Isso porque, segundo o autor, mães priorizam mais a educação do que os pais e, na presença de um padrasto ou de uma madrasta, os investimentos também são poucos pelo fato de os mesmos não sentirem que os filhos são seus e por isso não há um esforço maior pelas crianças de relacionamentos anteriores.

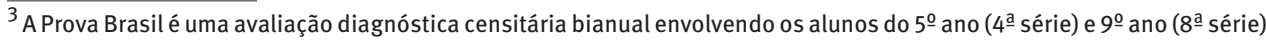
do ensino fundamental regular das escolas públicas que possuem, no mínimo, 20 alunos matriculados nos anos/séries avaliados. Disponível em: http://portal.mec.gov.br/prova-brasil. Acesso em: 20 set. 2019.
} 
Um estudo mais amplo apresentado no World family map 2015 discute o efeito da família sobre o desempenho escolar em contextos socioeconômicos mundiais diferentes. Em países em desenvolvimento, o desempenho escolar não se diferencia de maneira significativa segundo a estrutura familiar. Isso porque o acesso, a cobertura e a qualidade da educação nesses países não são bons o suficiente. Além de crianças e pais enfrentarem problemas de saúde e nutrição, o trabalho infantil para complementar a renda familiar não é incomum e acaba prejudicando o desempenho e a continuidade nos estudos. Nesses contextos, de países menos desenvolvidos, crianças que vivem em famílias monoparentais ou chefiadas por mulheres apresentam resultados escolares tão bons ou melhores do que aquelas pertencentes a famílias biparentais (CHILD TRENDS; SOCIAL TRENDS INSTITUTE, 2015).

Estudos brasileiros, em sua maioria, utilizam a proficiência (ou nota) de português ou matemática, ou os anos de estudos completos como medida de desempenho escolar, sendo que as características individuais, do ambiente familiar e da escola são consideradas para analisar os impactos na vida estudantil da criança enquanto determinantes cujos efeitos deseja-se avaliar.

Marteleto e De Souza (2012), ao investigarem o efeito do tamanho da família sobre os anos de estudos completos ao longo do tempo, utilizando os dados da Pesquisa Nacional por Amostra de Domicílios de 1977 a 2007, concluíram que, entre 1970 e 1990, período de elevadas taxas de fecundidade no Brasil e baixa escolaridade, o tamanho da família exercia uma influência positiva sobre os anos de estudos completos de adolescentes de 12 a 18 anos. A partir de 1996, esse efeito diminuiu até desaparecer em 2007, quando o trabalho infantil para complementar a renda familiar reduziu-se drasticamente. Assim, segundo os autores, o efeito do tamanho da família sobre o desempenho escolar da criança não é homogêneo ao longo do tempo e depende de variáveis sociais, econômicas e demográficas.

Martins e Teixeira (2016), empregando um modelo multinível aplicado aos dados da Prova Brasil de 2013, apontam que alunos do 5 ao 9을 ano do ensino fundamental que pertenciam a famílias compostas por pai e mãe tinham melhores resultados em português e matemática do que aqueles que viviam apenas com o pai, ou com a mãe. Adicionalmente, quando comparados lares monoparentais, os alunos que residiam somente com a mãe apresentavam resultados superiores àqueles que moravam apenas com o pai. Entretanto, ao observar o efeito do arranjo familiar sobre o desempenho em matemática dos alunos do 9ํㅡㅁ ano, percebe-se que o efeito é quase nulo, não sendo possível determinar a existência de uma associação entre desempenho escolar e o arranjo.

Palermo, Silva e Novellino (2014) também usaram modelagem multinível e encontraram evidências de que crianças vivendo em arranjos monoparentais tinham resultados escolares semelhantes aos daquelas que moravam com ambos os pais. Os autores concluíram ainda que o capital socioeconômico, cultural e social familiar tinha um poder explicativo conjunto superior apenas ao arranjo por si só. Tal resultado ratifica a necessidade de cuidado ao se analisar o efeito dos arranjos familiares sobre o desempenho e 
de como é importante entender de forma multilateral a influência da família na intensificação ou redução das desigualdades na educação.

De modo semelhante, Moreira e Jacinto (2017) destacam a importância de considerar o nível socioeconômico ao se avaliar o efeito da família sobre os resultados escolares. Para alunos que não conviviam com outros colegas de níveis socioeconômicos diferentes, havia perda na troca de experiências. Ou seja, a diversidade promove uma expansão de valores culturais que contribuem positivamente para o desempenho, ao passo que esse mesmo fator pode também ser um aprofundador de desigualdades, uma vez que quanto maior o nível socioeconômico das escolas analisadas, maior é a diferença de desempenho escolar entre os alunos de classes econômicas diferentes.

Alves et al. (2013) investigaram se as diferenças de desempenho escolar poderiam ser explicadas pela variação no perfil socioeconômico das famílias. Para tanto, os autores consideraram a posse de bens culturais, atividades cotidianas de escrita, ordem doméstica, práticas familiares de leitura, ambição escolar, interação pais/filhos, acompanhamento do dever de casa, ações na escolha do estabelecimento de ensino e modos de exercício da autoridade parental. 0 estudo mostrou que, em diferentes magnitudes, todos os fatores influenciavam o desempenho escolar das crianças, sendo que o nível socioeconômico sozinho, apesar de ser o fator mais fortemente associado ao desempenho, não seria suficiente para explicar a variação no desempenho escolar. Existem fatores referentes ao ambiente familiar, como diálogo entre pais e filhos, incentivo aos deveres de casa, por exemplo, que também contribuem para os resultados escolares.

Embora todos esses estudos apontem para a associação entre arranjos familiares e desempenho escolar de crianças, Nogueira (2005) destaca que tem crescido a quantidade de trabalhos que analisam os diversos efeitos das práticas educativas familiares sobre as trajetórias escolares dos alunos. Segundo a autora, essas práticas têm se revelado como mais preditoras dos destinos escolares do que a origem social, mesmo que exista uma forte correlação entre os dois tipos de variáveis. Isso porque, para Nogueira (2005), os pais mobilizam várias estratégias a fim de aumentar a competitividade e as chances de sucesso do filho, sobretudo em face do sistema escolar, o qual, por sua vez, ganha importância crescente como instância de legitimação individual e de definição dos destinos ocupacionais. E assim, segundo a autora, ao mesmo tempo que "a família vem penetrando crescentemente os espaços escolares, a escola também, por sua vez, alargou consideravelmente sua zona de interação com a instituição familiar" (NOGUEIRA, 2005, p. 574). Nesse sentido, pode-se pensar que a escola, bem como as variáveis relacionadas a ela, ganhando cada vez mais influência sobre a vida as crianças, apresentará também uma relação maior com seu desempenho escolar.

Existem, no entanto, outras perspectivas sobre o tema. Dessen e Polonia (2007) ressaltam que, apesar de o arranjo familiar ainda exercer influência relevante para o desenvolvimento da criança e de seu bem-estar, a escola também é vital para estímulo 
de valores que contribuem na formação como indivíduo e cidadão. Palermo, Silva e Novellino (2014) afirmam que as escolas possibilitariam a ampliação do capital cultural do aluno e assim diminuiriam a desigualdade dos diferentes tipos de antecedentes familiares das crianças e ampliariam as oportunidades de continuidade dos estudos.

Como demonstrado por esta breve revisão de literatura, existe associação entre o desempenho escolar e os arranjos familiares, com uma tendência de piores resultados para famílias reconstituídas. Entretanto, como destacado, o arranjo não é o único fator, ou o fator predominante, sobre a vida escolar. Elementos socioeconômicos, como a renda familiar e a escolaridade dos pais, e ainda outros componentes afetivos e culturais, como competências, valores e hábitos que os alunos recebem em casa, além do contexto escolar em que o aluno está inserido, também são apontados como determinantes do desempenho das crianças na escola.

\section{Metodologia}

\section{Base de dados e variáveis}

Foram utilizados os dados do Saeb que abrangem tanto os microdados da Avaliação Nacional da Educação Básica (Aneb) quanto da Avaliação Nacional do Rendimento Escolar (Anresc) do ano de 2015, pois os resultados da edição de 2017 ainda não estavam disponíveis no momento de elaboração deste trabalho. A Anresc (Prova Brasil) é uma avaliação censitária bianual, envolvendo os alunos do $5^{\circ}$ ano (4ํㅡㄹ série) e do 9ํㅜ ano ( $8^{a}$ série) do ensino fundamental regular das escolas públicas que possuem, no mínimo, 20 alunos matriculados nos anos/séries avaliados (BRASIL, 2017).

Estão no âmbito deste estudo os alunos do $5^{\circ}$ e 9 anos das escolas públicas do Brasil, cuja investigação é censitária na Prova Brasil. Escolhemos a nota de matemática como indicador do desempenho, seguindo a avaliação de Palermo, Silva e Novellino (2014) que já haviam indicado que o desempenho nesta disciplina teria seus efeitos mais bem captados do que em outras disciplinas. Foram utilizadas variáveis sociodemográficas, como cor, sexo, idade, além de informações sobre bens de consumo, estas últimas para construção de um indicador de nível socioeconômico. Consideramos também variáveis referentes aos arranjos familiares, bem como aquelas relacionadas aos hábitos culturais. A seleção dessas variáveis ocorreu com base na literatura de Dessen e Polonia (2007), Marteleto e De Souza (2012), Palermo, Silva e Novellino (2014), que apontaram a influência desses hábitos, além das características da família, sobre a vida escolar das crianças. No que se refere aos hábitos culturais, considerou-se se os pais leem com frequência e se incentivam o estudante a fazer as tarefas de casa, e ainda se o próprio aluno lê com frequência. Levou-se em conta também se o aluno já havia sido reprovado, se ele estava na série adequada à sua idade e se alguma vez havia abandonado a escola (mesmo que temporariamente). 
Para análise do nível socioeconômico dos alunos, foi utilizado o Critério de Classificação Econômica Brasil, também conhecido como Critério Brasil. Este índice busca estimar o poder de compra das pessoas e famílias urbanas brasileiras, dividindo-as em classes econômicas. Tal classificação é feita com base na posse de bens, sendo que cada bem possuído recebe uma pontuação e a soma dos pontos é usada para definir uma estratificação econômica (ABEP, 2018).

Para a criação da variável "tipos de arranjos familiares", destaca-se que o questionário não possibilitava identificar se pais e mães das crianças respondentes eram biológicos. Portanto, não é possível definir se as famílias biparentais são compostas por pais biológicos, se são famílias reconstituídas ou mesmo se ambos os pais são adotivos, por exemplo. Da mesma forma, quando o aluno respondia que morava apenas com a mãe e havia outro responsável homem no domicílio, não havia como verificar se esse responsável homem era um padrasto, um avô, um tio ou um irmão mais velho. Ciente dessas limitações, foi possível definir quatro arranjos familiares: mora com ambos os pais; mora com a mãe; mora com o pai; e outros. 0 arranjo "outros" foi necessário para incorporar as estruturas nas quais a criança não vivia nem com a mãe, nem com o pai, não sendo possível identificar seus responsáveis e outros parentes conviventes no mesmo domicílio.

\section{Modelagem estatística}

A abordagem estatística para analisar os dados escolares das crianças do $5^{0}$ e $9^{0}$ anos do ensino fundamental utiliza os modelos lineares hierárquicos (também conhecidos como modelos multiníveis), uma vez que, como apontado na revisão de literatura, o desempenho escolar dos alunos depende de um conjunto de variáveis que pertencem a diferentes níveis (características do aluno e ambiente familiar, escola, turma, etc.). Nesse caso, os modelos hierárquicos são mais adequados por descreverem unidades agrupadas dentro de outras unidades maiores, permitindo, dessa forma, mensurar a influência da unidade maior sobre o indivíduo analisado.

Os modelos hierárquicos definem uma relação estatística linear entre a variável resposta $y$ e as variáveis explicativas, reconhecendo que os dados são estruturados em hierarquias, de tal forma que as unidades de um mesmo nível pertencem também a uma unidade de nível mais alto, violando, portanto, a suposição de independência entre as observações.

Nesse trabalho foi aplicado o modelo de efeitos fixos de dois níveis - aluno e escola -, pois, conforme mostra a Tabela 1, a componente de variação que podia ser decomposta como nível turma (no modelo de três níveis) é residual. 
TABELA 1

Partição da variância de acordo com os níveis do modelo nulo para o desempenho em matemática

\begin{tabular}{|c|c|c|c|c|c|c|}
\hline \multirow[b]{2}{*}{ Modelo nulo } & \multirow[b]{2}{*}{ Níveis } & \multirow[b]{2}{*}{ Variância } & \multicolumn{2}{|c|}{$5 \div$ ano } & \multicolumn{2}{|c|}{$9^{\circ}$ ano } \\
\hline & & & $\begin{array}{l}\text { Efeito } \\
\text { turma }\end{array}$ & $\begin{array}{l}\text { Efeito } \\
\text { escola }\end{array}$ & $\begin{array}{l}\text { Efeito } \\
\text { turma }\end{array}$ & $\begin{array}{l}\text { Efeito } \\
\text { escola }\end{array}$ \\
\hline \multirow{4}{*}{ Modelos com dois níveis } & Alunos & 1526,66 & \multirow{2}{*}{0,26} & \multirow{2}{*}{-} & \multirow{2}{*}{0,17} & \multirow{2}{*}{-} \\
\hline & Turmas & 563,82 & & & & \\
\hline & Alunos & 1585,71 & \multirow{2}{*}{-} & \multirow{2}{*}{0,25} & \multirow{2}{*}{-} & \multirow{2}{*}{0,15} \\
\hline & Escolas & 529,41 & & & & \\
\hline \multirow{3}{*}{ Modelo com três níveis } & Alunos & 1526,67 & \multirow{3}{*}{0,06} & \multirow{3}{*}{0,23} & \multirow{3}{*}{0,05} & \multirow{3}{*}{0,13} \\
\hline & Turmas & 104,41 & & & & \\
\hline & Escolas & 470,72 & & & & \\
\hline
\end{tabular}

Fonte: Inep. Microdados do Sistema de Avaliação Escolar Brasileiro 2015.

0 modelo de efeitos fixos com dois níveis assume que o desempenho tem uma relação linear com as variáveis, porém, para cada escola, há um intercepto diferente, tal que: $y_{i k}=\beta_{0 k}+\beta_{1} x_{1 i k}+\beta_{2} x_{2 i k}+\ldots+\beta_{j} x_{j i k}+\ldots+\beta_{p-1} x_{p-1 i k}+e_{i k}$,

Onde:

$y_{i k}$ é o desempenho do $i$-ésimo aluno da $k$-ésima escola, com $i=1, \ldots, n_{k}$ e $k=1, \ldots, K$;

$\beta_{0 k}$ é intercepto do modelo para a k-ésima escola;

$\beta_{j}$ é o coeficiente de regressão para a j-ésima variável do modelo com $j=1, \ldots, p$-1;

$x_{j i k}$ é a j-ésima covariável associada aos efeitos fixos do i-ésimo aluno da $k$-ésima escola;

$e_{i k}$ é erro aleatório associado ao i-ésimo aluno da $k$-ésima escola, representando assim o desvio da proficiência do aluno $i$ em relação à média de sua escola; $e_{i k} \sim N\left(0, \sigma_{e}^{2}\right)$.

Os modelos hierárquicos são adequados para a análise de dados educacionais, pois não apenas consideram o aluno e seu histórico, mas também incorporam o efeito da escola. Além disso, tais modelos levam em conta que alunos não são independentes entre si e que os estudantes podem ter desempenhos semelhantes de acordo com a escola em que estudam (PALERMO; SILVA; NOVELLINO, 2014). Os modelos empregados neste artigo foram ajustados utilizando o software $R$.

\section{Análise exploratória do desempenho em matemática segundo características dos estudantes e ambiente escolar}

Na Tabela 2 é possível verificar que, tanto para os alunos do $5^{\circ}$ ano quanto para aqueles do 9ํano, o tipo de família prevalente é o composto por ambos os pais, seguido pelo arranjo monoparental formado pela mãe. Esses resultados são consoantes à literatura da área que aponta que o tipo de família mais frequente é o biparental, seguido pelas famílias monoparentais com a presença da mãe (CHILD TRENDS; SOCIAL TRENDS INSTITUTE, 2015; ALVES; CAVENAGHI, 2012). 
TABELA 2

Distribuição dos alunos, por ano escolar, segundo arranjos familiares Brasil - 2015

\begin{tabular}{lcc}
\multicolumn{1}{c}{ Arranjos familiares } & $\mathbf{5 0}$ ano & Em porcentagem \\
\hline Mora com ambos os pais & 59,7 & $\mathbf{9}$ ano \\
Mora apenas com a mãe & 23,3 & 26,2 \\
Mora apenas com o pai & 1,2 & 1,8 \\
Outros arranjos & 15,8 & 15,1 \\
\hline
\end{tabular}

Fonte: Inep. Microdados do Sistema de Avaliação Escolar Brasileiro 2015.

Os Gráficos 1 e 2 apresentam, respectivamente, a distribuição das notas de matemática no 5ํㅜ e 9anos, segundo o número de pessoas na família do aluno. Observa-se que, para ambas as séries, não há diferenças acentuadas entre as proficiências medianas para os alunos cujo tamanho da família varia entre 2 e 4 pessoas. Entretanto, um pior desempenho é encontrado quando o aluno declarava morar sozinho, bem como residir com 5 ou 6 ou mais pessoas no domicílio.

GRÁFICO 1

Distribuição da nota de matemática para 5ํano do ensino fundamental, segundo o número de pessoas na família

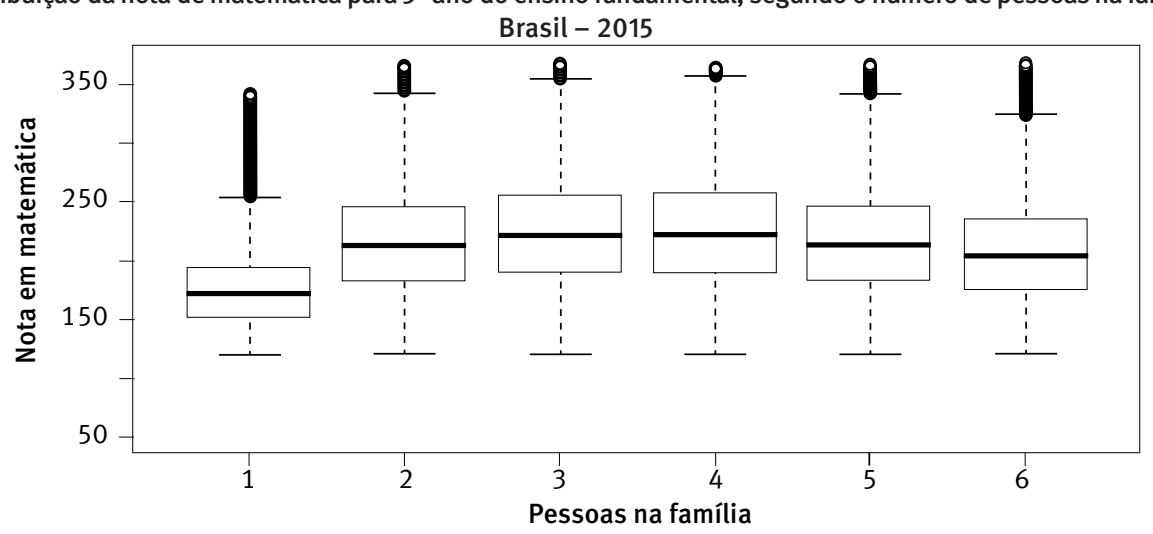

Fonte: Inep. Microdados do Sistema de Avaliação Escolar Brasileiro 2015.

GRÁFICO 2

Distribuição da nota de matemática para o 9ํano do ensino fundamental, segundo o número de pessoas na família Brasil - 2015

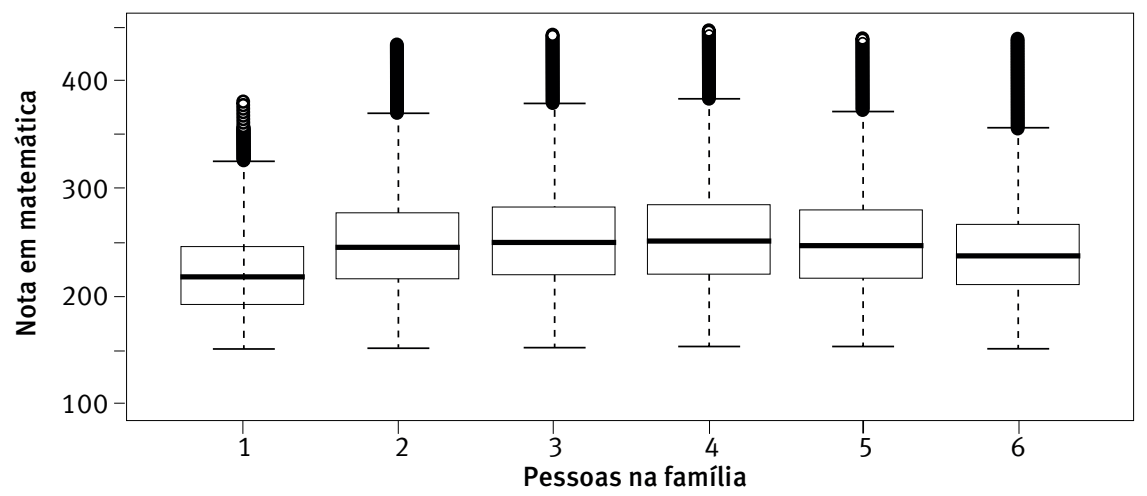

Fonte: Inep. Microdados do Sistema de Avaliação Escolar Brasileiro 2015. 
A análise dos indicadores de reprovação, evasão e abandono (Tabela 3) mostra que, para o 5ํano, quando há 3 ou 4 pessoas na família, a incidência de reprovação e evasão, assim como a defasagem, atinge os menores patamares. Por outro lado, os piores resultados são encontrados no caso do aluno que declarava morar sozinho. 0 mesmo comportamento é observado entre os alunos do 9ํano para os indicadores de reprovação e evasão. Já o indicador de defasagem registrou seu menor valor para estudantes do 90 ano que declararam morar sozinhos.

TABELA 3

Distribuição dos alunos de 5ำ e 9ํa anos do ensino fundamental, por número de pessoas na família, segundo indicadores de reprovação, evasão e abandono

Brasil - 2015

Em porcentagem

\begin{tabular}{clrrrrrr}
\hline \multirow{2}{*}{$\begin{array}{c}\text { Anos e indicadores } \\
\text { educacionais }\end{array}$} & \multicolumn{6}{c}{ Número de pessoas na família } \\
\cline { 2 - 7 } & Reprovação & $\mathbf{1}$ & $\mathbf{2}$ & $\mathbf{3}$ & $\mathbf{4}$ & $\mathbf{5}$ & $\mathbf{6}$ ou mais \\
\hline \multirow{3}{*}{ 50 ano } & 49,9 & 24,5 & 20,0 & 19,4 & 25,1 & 31,4 \\
& Evasão & 32,2 & 9,3 & 6,1 & 5,5 & 7,0 & 9,1 \\
& Defasagem & 70,6 & 60,6 & 58,5 & 58,5 & 63,5 & 68,6 \\
\hline \multirow{2}{*}{ 90 ano } & Reprovação & 54,1 & 33,8 & 28,2 & 25,9 & 30,4 & 36,8 \\
& Evasão & 22,7 & 7,2 & 5,1 & 4,2 & 5,2 & 7,0 \\
\hline
\end{tabular}

Fonte: Inep. Microdados do Sistema de Avaliação Escolar Brasileiro 2015.

O Gráfico 3 apresenta a distribuição das notas de matemática no $5^{0}$ e $9^{\circ}$ anos segundo arranjos familiares. Constata-se que não há variação de destaque entre as medianas das distribuições das notas em ambos os casos. Uma sutil diferença pode ser notada ao se comparar a distribuição de notas do arranjo biparental com aquele formado apenas pelo pai para os alunos do $5^{\circ}$ ano.

GRÁFICO 3

Distribuição das notas de matemática para o 5ำ e 9ํanos do ensino fundamental, segundo arranjos familiares

Brasil - 2015
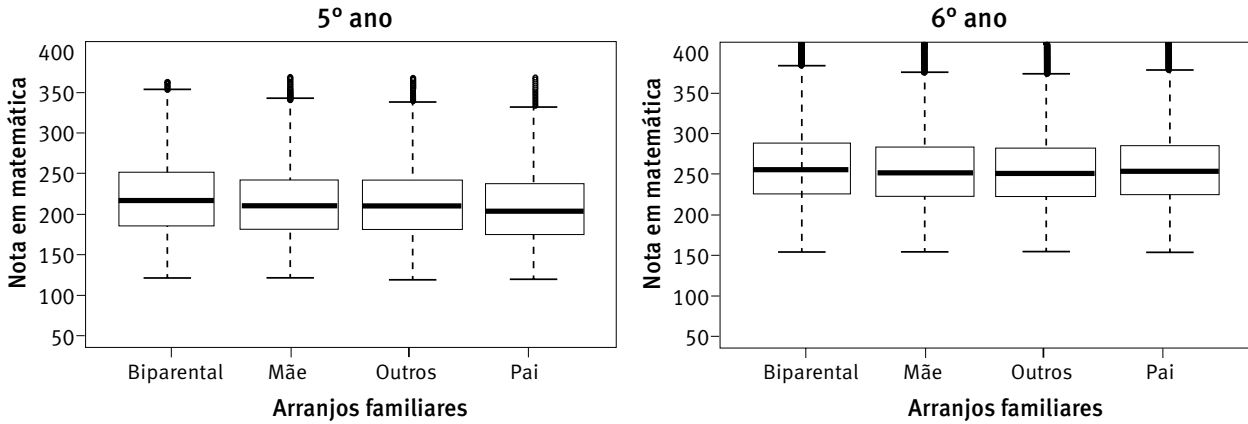

Fonte: Inep. Microdados do Sistema de Avaliação Escolar Brasileiro 2015. 
Analisando as taxas de reprovação, evasão e defasagem segundo a composição das famílias, observam-se variações (Tabela 4). Para o 5ํano, esses indicadores são sempre menores dentre os alunos que vivem em arranjos biparentais e maiores para aqueles que moram apenas com o pai. No 9 ํㅜ ano, notam-se percentuais de reprovação e evasão bem mais elevados se comparados aos do $5^{0}$ ano. Destaca-se também que, para os alunos do 9ำ ano, o indicador de evasão é maior para aqueles em famílias biparentais.

A distribuição dos indicadores de defasagem, evasão e reprovação indica que há um efeito diferencial entre os tipos de família que se reflete na vida escolar das crianças. É possível perceber que, em arranjos em que há apenas o pai, tanto no $5^{\circ}$ quanto no $9^{\circ}$ ano, os indicadores sugerem uma vulnerabilidade maior quando comparados aos arranjos biparentais, mesmo nos casos dos compostos apenas pela mãe.

TABELA 4

Distribuição dos alunos de 5ำ e 9ํanos do ensino fundamental, por tipo de arranjo familiar, segundo indicadores de reprovação, evasão e abandono Brasil - 2015

Em porcentagem

\begin{tabular}{|c|c|c|c|c|c|}
\hline \multirow{2}{*}{\multicolumn{2}{|c|}{ Anos e indicadores educacionais }} & \multicolumn{4}{|c|}{ Tipos de arranjo familiar } \\
\hline & & Biparental & Mãe & Outros & Pai \\
\hline \multirow{3}{*}{$5^{\circ}$ ano } & Reprovação & 20,7 & 27,3 & 29,5 & 35,7 \\
\hline & Evasão & 5,8 & 8,0 & 10,5 & 15,0 \\
\hline & Defasagem & 59,0 & 65,7 & 67,3 & 69,4 \\
\hline \multirow{3}{*}{90 ano } & Reprovação & 85,8 & 86,3 & 84,2 & 82,7 \\
\hline & Evasão & 62,7 & 55,5 & 57,5 & 57,4 \\
\hline & Defasagem & 59,0 & 65,7 & 67,3 & 69,4 \\
\hline
\end{tabular}

Fonte: Inep. Microdados do Sistema de Avaliação Escolar Brasileiro 2015.

No que se refere às características das escolas, é possível observar na Tabela 5 que aquelas com melhor desempenho médio estão localizadas na área urbana das regiões Sudeste e Sul e são escolas federais. Medeiros e Oliveira (2014), analisando a média de anos de estudo a fim de verificar a desigualdade inter-regional e intrarregional, afirmam que as diferenças regionais de escolaridade são significativas, revelando desigualdade na qualidade do ensino ofertado em cada região. A partir dos dados da Prova Brasil, Resende et al. (2011) analisaram o desempenho escolar segundo a dependência administrativa do estabelecimento de ensino (privado, municipal, estadual ou federal). Os autores verificaram que os alunos da rede privada tinham melhor desempenho na Prova Brasil, seguidos pelos estudantes das redes federal e depois estadual, sendo que o menor desempenho foi encontrado na rede municipal. 
TABELA 5

Distribuição das escolas e proficiência média em matemática, por ano de ensino, segundo região, dependência administrativa e localidade

Brasil - 2015

\begin{tabular}{|c|c|c|c|c|c|}
\hline \multirow{2}{*}{\multicolumn{2}{|c|}{ Características da escola }} & \multicolumn{2}{|c|}{50 ano } & \multicolumn{2}{|c|}{ 9ㅇa ano } \\
\hline & & \multirow{2}{*}{$\begin{array}{c}\begin{array}{c}\text { Distribuição } \\
\text { (\%) }\end{array} \\
8,3\end{array}$} & \multirow{2}{*}{$\begin{array}{c}\begin{array}{c}\text { Proficiência } \\
\text { média }\end{array} \\
222,9\end{array}$} & \multirow{2}{*}{$\begin{array}{c}\begin{array}{c}\text { Distribuiç̧ão } \\
(\%)\end{array} \\
7,6\end{array}$} & \multirow{2}{*}{$\begin{array}{c}\text { Proficiência } \\
\text { média }\end{array}$} \\
\hline \multirow{5}{*}{ Região } & Centro-Oeste & & & & \\
\hline & Nordeste & 21,5 & 205,9 & 23,7 & 245,8 \\
\hline & Norte & 10,0 & 207,4 & 8,5 & 245,4 \\
\hline & Sudeste & 43,8 & 236,3 & 47,5 & 260,6 \\
\hline & Sul & 16,2 & 236,3 & 12,5 & 265,6 \\
\hline \multirow{3}{*}{$\begin{array}{l}\text { Dependência } \\
\text { administrativa }\end{array}$} & Estadual & 21,6 & 231,3 & 60,8 & 257,2 \\
\hline & Federal & 0,1 & 261,6 & 0,2 & 323,7 \\
\hline & Municipal & 78,3 & 224,2 & 38,9 & 254,8 \\
\hline \multirow{2}{*}{ Localidade } & Rural & 7,9 & 206,2 & 6,9 & 245,1 \\
\hline & Urbana & 92,1 & 227,4 & 93,1 & 257,2 \\
\hline
\end{tabular}

Fonte: Inep. Microdados do Sistema de Avaliação Escolar Brasileiro 2015.

\section{Análise dos resultados da modelagem estatística para desempenho em matemática}

A Tabela 6 apresenta os coeficientes estimados, e respectivos p-valores indicando significância estatística, dos modelos hierárquicos desenvolvidos para investigar a associação do desempenho em matemática com características do aluno, do ambiente familiar e da escola.

Em média, a nota de matemática esperada é de 170,77 pontos para um aluno do 50 ano, em um arranjo familiar biparental, do sexo masculino, branco, residente em área urbana da região Sudeste, cujo domicílio pertence à classe econômica $D-E$, que navega na internet/ joga/assiste televisão menos de uma hora por dia, realiza menos de uma hora de trabalhos domésticos em casa, que trabalha, que entrou na escola na creche e estudou somente em escola pública, que faz sempre ou quase sempre os deveres de português e matemática e cujos professores também corrigem sempre ou quase sempre os exercícios de casa, que não reprovou e nunca evadiu, usa a biblioteca sempre ou quase sempre, cujos pais nunca estudaram e os filhos não os veem lendo com frequência. Para alunos do 9ํano que compartilham o mesmo perfil, a nota média de matemática esperada é de 260,25 pontos.

Analisando os arranjos familiares, a categoria de referência é a dos alunos que moram com ambos os pais. No $5^{\circ}$ ano, para o aluno que declarou morar apenas com a mãe, sua nota era em média 1,63 ponto inferior à de um aluno que vivia com ambos os pais. Além disso, para o aluno que residia apenas com o pai, a nota era em média 1,06 ponto menor do que a daquele que morava com ambos os pais. Novamente, os efeitos dos fatores são atenuados no 9ำ ano, com coeficientes estimados assumindo valores negativos módicos para todos os arranjos em comparação com a situação biparental. Conclui-se, então, que o efeito da família sobre a proficiência média em matemática, apesar de estatisticamente significativo, é muito pequeno, em especial para alunos do $9^{\circ}$ ano, e que a influência do 
arranjo familiar sobre a nota diminui de acordo com o progresso nas séries escolares. Os resultados são coerentes com o estudo de García e Oliveira (2011), que observaram como os efeitos da família sobre o desempenho mudam de acordo com a série escolar analisada.

Considerando também a escolaridade dos pais - variável que faz parte das características da família -, verificou-se efeito positivo na proficiência de matemática para alunos do

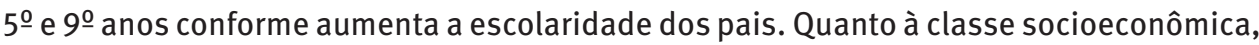
estima-se que alunos do $5^{\circ}$ ano nos estratos A-B e C possuem proficiência média em matemática em torno de 4 pontos superior à daqueles no estrato $\mathrm{D}-\mathrm{E}$.

Outro fator que foi controlado para avaliar a influência da família na proficiência foram os hábitos familiares. Para o 50 ano, quando os pais tinham o hábito de ler frequentemente, incentivavam o aluno a fazer os exercícios de casa e a não faltar às aulas, esses fatores tinham efeito positivo sobre a nota, embora tenham um efeito menor do que a escolaridade dos pais. Já no 9 ํano, essas mesmas variáveis apresentaram coeficientes negativos, apesar de significativos, indicando que o efeito dessas variáveis não é o mesmo ao longo da vida escolar.

Sobre o trabalho doméstico, para os alunos do 50 ano que declaravam trabalhar mais de três horas em afazeres do lar, a nota de matemática diminuía em média 11,22 pontos em relação a quem fazia menos de uma hora de trabalhos domésticos. No 9ํano esse efeito foi menor.

Ao se considerar o histórico escolar, observa-se uma redução na proficiência média em matemática quando o aluno tinha sido reprovado ou já tinha abandonado a escola em algum momento. Esse resultado negativo pode estar relacionado à menor motivação para a aprendizagem desses alunos repetentes ou evadidos. Além disso, o atraso ocasionado pela reprovação em algum ponto da trajetória escolar também pode fazê-los se sentir, de alguma forma, prejudicados em relação aos demais colegas.

Ainda sobre a trajetória do aluno, observou-se que a nota de matemática era em média maior quanto mais cedo ele ingressasse na escola, embora esse feito seja mais evidente no $5^{\circ}$ ano. Adicionalmente, a proficiência de um aluno que estudou em escola pública e particular era em média menor em relação àquele que estudou somente na escola pública ou somente na escola particular. № 9ํan ano os efeitos são muito pequenos e próximos de zero no que se refere a essas variáveis. Tal resultado ainda é pouco estudado na literatura e pode indicar uma dificuldade de adaptação dos alunos que saem da escola particular para a pública; seja uma dificuldade de se integrar à turma e aos colegas da escola na rede pública, ou mesmo ao sistema de ensino anterior, do colégio particular, que poderia ser mais demandante.

Além disso, tanto para alunos do $5^{\circ}$ ano quanto para os do $99^{\circ}$ ano, as notas são em média superiores quando os professores corrigem sempre os exercícios e quando o aluno fazia o dever de casa de português ou de matemática sempre ou quase sempre. Os hábitos de leitura dos pais, o incentivo nas atividades escolares e os hábitos de leitura do próprio aluno também têm efeito positivo sobre a média da proficiência em matemática.

Ao se considerarem as características da escola, o acréscimo de um ponto na taxa de participação da escola no exame da Prova Brasil está associado a um aumento de 47,04 pontos na média da nota de matemática, no $5^{\circ}$ ano, e de 4,06 pontos, no 9 음 ano. 0 efeito 
dessa variável do nível da escola é maior quando comparado a todos os outros do nível do aluno. A taxa de participação indica também o engajamento da escola com a avaliação e melhoria de suas estruturas e métodos, sendo que a magnitude desse efeito ratifica a importância da escola no desempenho individual do aluno. Sobre as características geográficas, alunos de localidades urbanas tinham, em média, proficiência maior do que os de localidade rural, assim como alunos da região Sudeste, e também Sul, em relação às demais.

TABELA 6

Coeficientes estimados dos modelos hierárquicos de proficiência em matemática para o 5ㅇ e 9으 anos do ensino fundamental e respectivo $\mathrm{P}$-valor, segundo variáveis explicativas Brasil - 2015

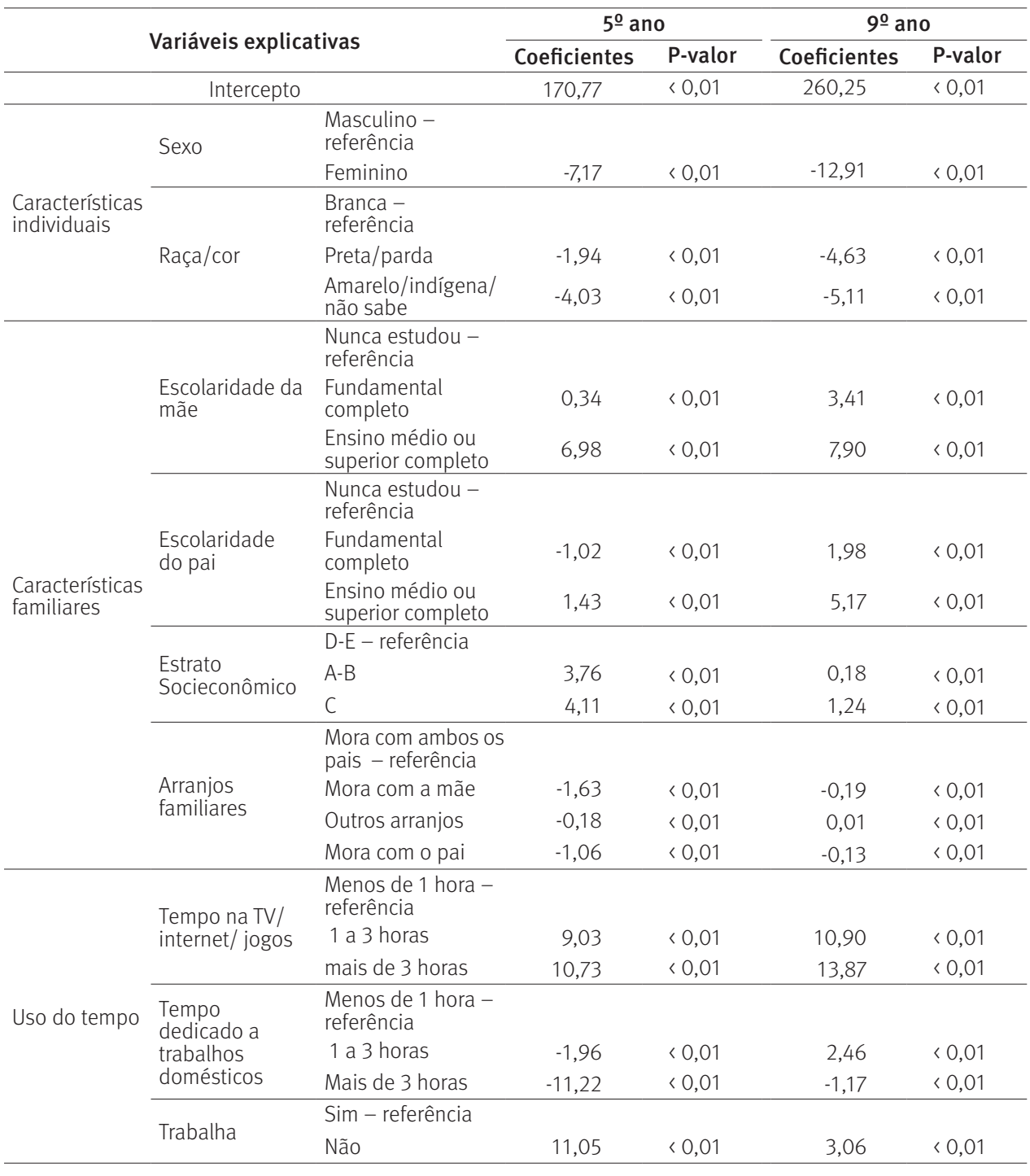




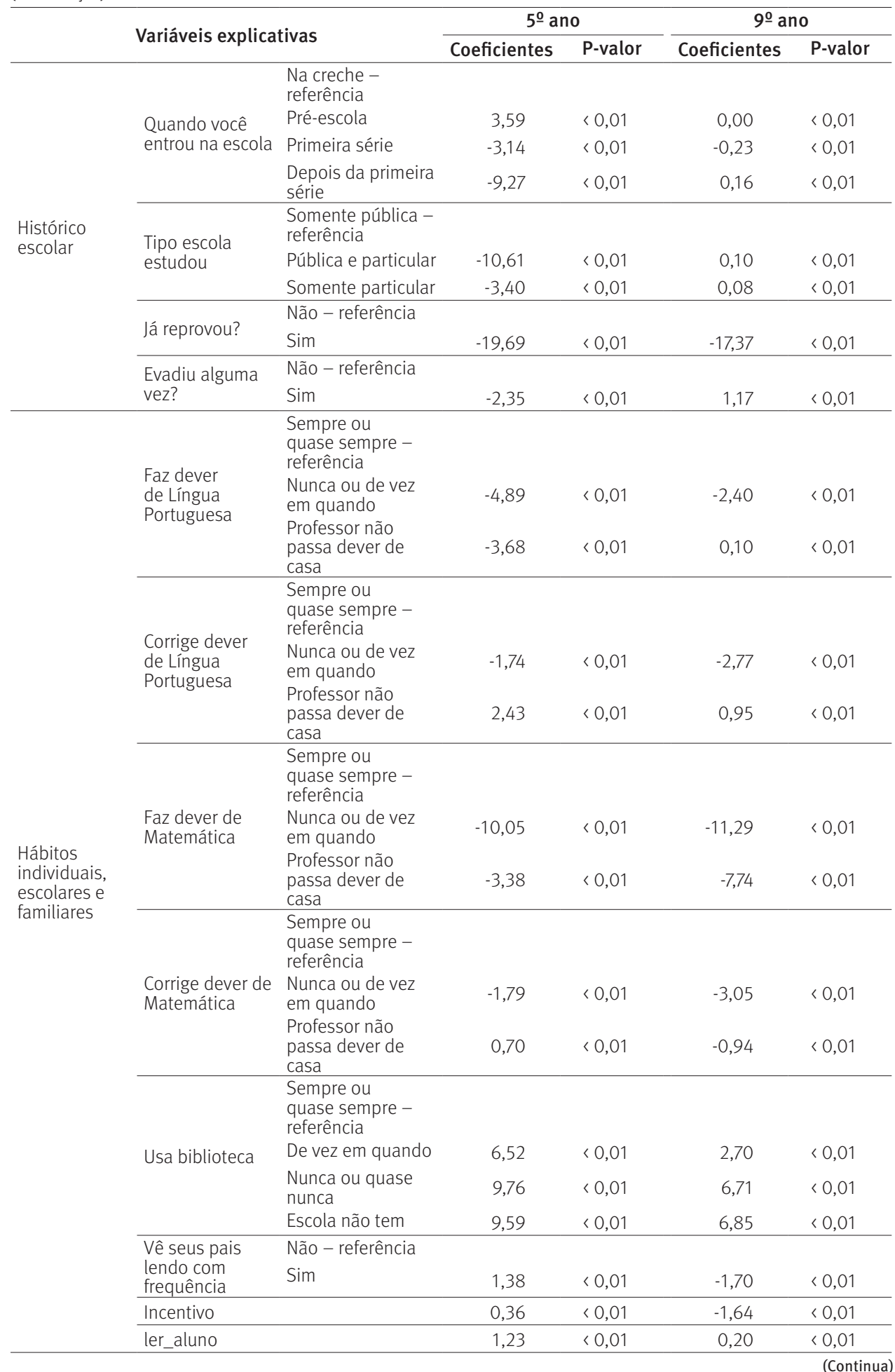




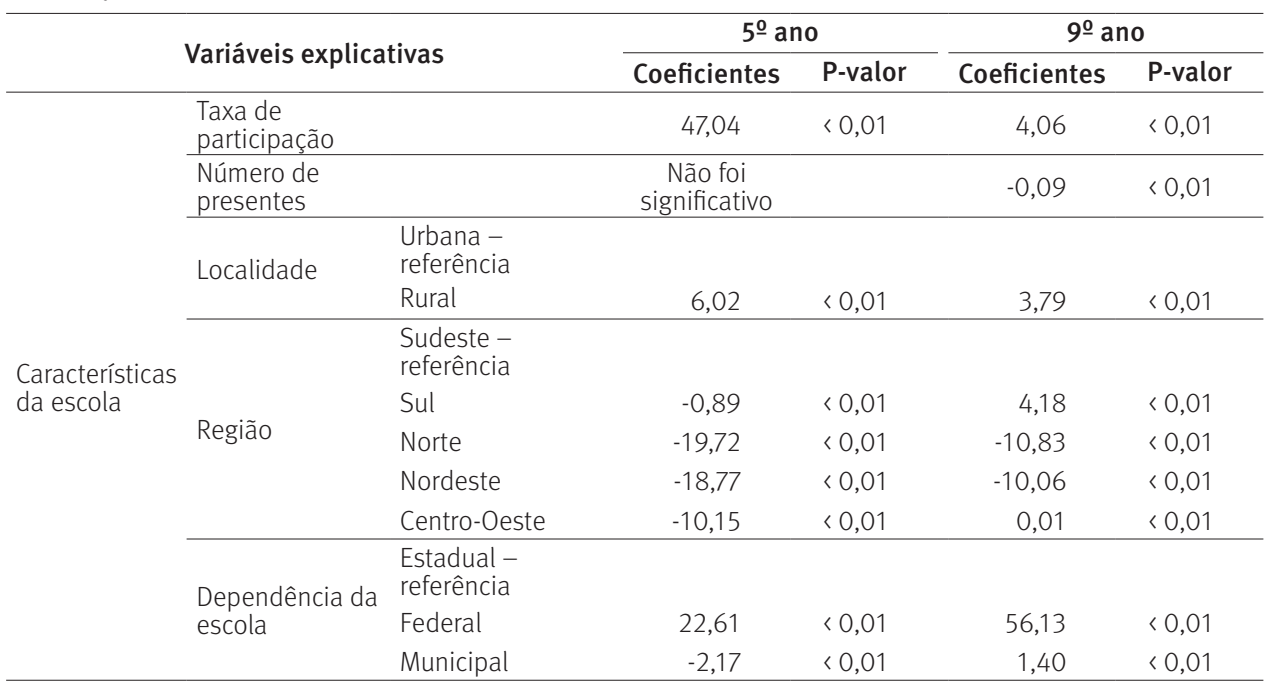

Fonte: Inep. Microdados do Sistema de Avaliação Escolar Brasileiro 2015.

\section{Considerações finais}

Uma primeira conclusão do trabalho foi que, ao controlar os efeitos do ambiente escolar, as composições dos arranjos familiares têm pouca influência sobre a proficiência média em matemática de alunos das escolas públicas, tanto do 5 ํ quanto do 9 ano. Apesar de pequeno, esse efeito mostra que alunos que pertenciam a lares biparentais tinham proficiência média em matemática levemente maior do que aqueles em lares monoparentais. Além disso, foram observadas diferenças nesse efeito de acordo com a série escolar frequentada, sendo que para o 9ำ ano o efeito estimado foi ainda menor. Embora pouco impactantes para a nota, esses resultados, ao contrário do que se esperava, mostram que, no Brasil, para os alunos nos anos do ensino fundamental analisados, os arranjos monoparentais não oferecem as mesmas condições para o desempenho escolar do que os do tipo biparental.

No entanto, esse achado não deve ser analisado isoladamente, pois foram apresentadas evidências de que os indicadores relacionados às características individuais da criança, às características da escola, aos hábitos de assistência dos responsáveis, ao estudo da criança, bem como ao nível socioeconômico e à escolaridade dos pais, possuem um alcance superior sobre o desempenho escolar do aluno, do que apenas a composição do arranjo em si.

Pais com maior escolaridade, que tinham o hábito de ler frequentemente, que incentivavam o aluno a fazer os exercícios de casa, a não faltar às aulas e o hábito de ler do aluno contribuíam para o aumento da nota média em matemática para os estudantes de 5 으. ano. Além desses, os fatores associados ao exercício do trabalho doméstico ou do trabalho fora de casa também contribuíram negativamente para o desempenho médio em matemática. Adicionalmente, fazer exercícios de português ou de matemática em casa, 
ter professores de português e matemática que corrigem os exercícios, nunca ter sido reprovado ou abandonado a escola anteriormente tiveram o efeito de incrementar a nota média de matemática em ambas as séries.

Por fim, as características da escola apresentaram grande impacto sobre a proficiência média em ambas as etapas de ensino, ressaltando-se a taxa de participação da escola no exame da Prova Brasil, bem como a localização e o tipo de dependência administrativa da escola, com destaque para as escolas federais da zona urbana da região Sudeste. Tais resultados apontam para a relevância do ambiente escolar para o delineamento do desempenho escolar das crianças.

Esses elementos ratificam a existência de uma gama de fatores, para além do arranjo familiar, que auxiliam ou prejudicam o desempenho escolar do aluno, mostrando a importância de um ambiente que ofereça condições da criança se manter na escola, sem a necessidade de trabalhar, ajudar nos afazeres domésticos, que dê espaço para o aluno se dedicar aos estudos, se informar e cujos pais incentivam o bom resultado educacional.

Os resultados demonstraram o mérito de analisar e observar mais sobre as relações familiares e o contexto da escola, do que especificamente o arranjo em si. Isto é, se há incentivo por parte dos pais, se há demonstração de interesse e acompanhamento do desempenho do aluno, se a criança é estimulada à leitura pelos mesmos, se ela é responsável com suas atividades escolares, se os professores dão a assistência necessária em sala de aula por meio das tarefas, melhor será o desempenho do aluno.

Registra-se que existem ainda outros elementos que não foram possíveis de serem captados nesta análise, como a harmonia do lar e se a criança sofre ou não pressões e ansiedades decorrentes de dissoluções dentro da casa. Esse conjunto de elementos poderia ajudar a avaliar a existência de efeitos diferenciados na estrutura e hábitos familiares sobre o desempenho escolar.

\section{Referências}

ABEP - Associação Brasileira de Empresas de Pesquisa. Critério de Classificação Econômica Brasil. Abep, 2018.

ALVES, J.; CAVENAGHI, S. Tendências demográficas, dos domicílios e das famílias no Brasil. Aparte IE/UFRJ, v. 1, p. 1-31, 2012.

ALVES, M. T. G.; NOGUEIRA, M. A.; NOGUEIRA, C. M. M.; RESENDE, T. F. Fatores familiares e desempenho escolar: uma abordagem multidimensional. Dados - Revista de Ciências Sociais, v. 56, n. 3, p. 571-603, 2013.

AMATO, P. R. The consequences of divorce for adults and children. Journal of Marriage and Family, v. 62, n. 4 p. 1269-1287, Nov. 2000.

BARBOSA, M.; FERNANDES, C. Modelo multinível: uma aplicação a dados de avaliação educacional. Estudos em Avaliação Educacional, n. 22, p. 135-154, 2000. 
BARBOZA, E. A composição das turmas e o desempenho escolar na rede pública de ensino de Minas Gerais. Tese (Doutorado em Educação) - Faculdade de Educação, PUC Rio, Rio de Janeiro, 2006.

BASSETTO, C. F. Background familiar e desempenho escolar: uma abordagem com variáveis binárias a partir dos resultados do Saresp. Revista Brasileira de Estudos de População, v. 36, 2019.

BELLER, E. Bringing intergenerational social mobility research into the twenty-first century: why mothers matter. American Sociological Review, v. 74, n. 4, p. 507-528, 2009.

BERQUÓ, E.; OLIVEIRA, M. Casamento em tempos de crise. Revista Brasileira de Estudos de População, v. 9, n. 2, p. 155-167, 2014.

BERQUÓ, E.; CAVENAGHI, S. Mapeamento socioeconômico e demográfico dos regimes de fecundidade no Brasil e sua variação entre 1991 e 2000. In: XIV ENCONTRO NACIONAL DE ESTUDOS POPULACIONAIS. Anais [...]. Caxambu: Abep, 2004.

BONAMINO, A. Os efeitos das diferentes formas de capital no desempenho escolar: um estudo à luz de Bourdieu e de Coleman. Revista Brasileira de Educação, v. 15, n. 45, p. 487-499, 2010.

BROWN, S. Family structure and child well-being: the significance of parental cohabitation. Journal of Marriage and Family, v. 66, n. 2, p. 351-367, 2004.

CHILD TRENDS; SOCIAL TRENDS INSTITUTE. World family map 2015: mapping family change and child well-being outcomes. New York; Barcelona, 2015. Disponivel em: https://www.childtrends. org/wp-content/uploads/2015/09/2015-39WorldFamilyMap2015.pdf. Acesso em: 8 mar. 2019.

DESSEN. M. A.; POLONIA, A. C. A família e a escola como contextos de desenvolvimento humano. Paidéia (Ribeirão Preto), v. 17, n. 36, jan./abr. 2007.

FOMBY, P.; CHERLIN, A. Family instability and child well-being. American Sociological Review, v. 72, n. 2, p. 181-204, 2007.

GARCÍA, B.; OLIVEIRA, O. Family changes and public policies in Latin America. Annual Review of Sociology, v. 37, p. 593-611, 2011.

GARNEAU, C. Family structure, social capital, and educational outcomes in two-parent families. Dissertação (Mestrado em Ciências da Família e da Criança) - Faculdade de Ciências Humanas, Universidade Estadual da Flórida, EUA, 2012.

GRIESBACH, D.; AMOS, A.; CURRIE, C. Adolescent smoking and family structure in Europe. Social Science \& Medicine, v. 56, n. 1, p. 41-52, 2003.

HOX, J. Applied multilevel analysis. TT-publikaties, 1995.

INEP - Instituto Nacional de Estudos e Pesquisas Educacionais Anísio Teixeira. Microdados da Aneb e da Anresc 2015. Brasília: Inep, 2017. Disponível em: http://portal.inep.gov.br/basicalevantamentos-acessar. Acesso em: 30 jan. 2017.

LESTHAEGHE, R. The second demographic transition: a concise overview of its development. Proceedings of the National Academy of Sciences, v. 111, n. 51, p. 18112-18115, 2014.

LIMA, L.; DOS SANTOS, D. Influência paterna na alfabetização. In: XLII ENCONTRO NACIONAL DE ECONOMIA. Anais [...]. Natal: Associação Nacional dos Centros de Pós-Graduação em Economia - Anpec, 2014. 
LIMA, L. Arranjos familiares e desempenho escolar de alunos do 5우 e 9ํan a no Brasil em 2015. Dissertação (Mestrado em População, Território e Estatísticas Públicas) - Programa de Pósgraduação População, Território e Estatísticas Públicas, Escola Nacional de Ciências Estatísticas, Rio de Janeiro, 2018.

LUZ, L. Os determinantes do desempenho escolar: a estratificação educacional e o efeito valor adicionado. In: XV ENCONTRO NACIONAL DE ESTUDOS POPULACIONAIS. Anais [...]. Belo Horizonte: Abep, 2006.

MACHADO, A. Qualidade do ensino em matemática: determinantes do desempenho de alunos em escolas públicas estaduais mineiras. Revista da Anpec, v. 9, n. 1, 2008.

MARTELETO, L.; DE SOUZA, L. The changing impact of family size on adolescents' schooling: assessing the exogenous variation in fertility using twins in Brazil. Demography, v. 49, n. 4, p. 1453-1477, 2012.

MARTINS, J.; TEIXEIRA, E. As estruturas familiares afetam o desempenho escolar no Brasil? In:XVII SEMINÁRIO SOBRE A ECONOMIA MINEIRA. Anais [...]. Adamantina: Cedeplar/UFMG, 2016.

MCLANAHAN, S. Diverging destinies: how children are faring under the second demographic transition. Demography, v. 41, n. 4, p. 607-627, 2004.

MCLANAHAN, S.; PERCHESKI, C. Family structure and the reproduction of inequalities. Annual Review of Sociology, v. 34, p. 257-276, 2008.

MCLANAHAN, S.; TACH, L.; SCHNEIDER, D. The causal effects of father absence. Annual Review of Sociology, v. 39, p. 399-427, 2013

MEDEIROS, M.; OLIVEIRA, L. Desigualdades regionais em educação: potencial de convergência. Sociedade e Estado, v. 29, n. 2, p. 561-585, 2014.

MENEZES-FILHO, N. Os determinantes do desempenho escolar do Brasil. São Paulo: Instituto Futuro Brasil/Ibemec, FEA/USP, 2007.

MOREIRA, K.; JACINTO, P. B. Determinantes da proficiência em matemática no Rio Grande do Sul: uma análise a partir de modelos hierárquicos. Ensaios FEE, v. 38, n. 1, p. 7-34, 2017.

MURPHY, M. Long-term effects of the demographic transition on family and kinship networks in Britain. Population and Development Review, v. 37, p. 55-80, 2011.

NEY, M.; DE SOUZA, P.; PONCIANO, N. Desigualdade de acesso à educação e evasão escolar entre ricos e pobres no Brasil rural e urbano. InterSciencePlace, v. 1, n. 13, 2015.

NOGUEIRA, M. A. A relação família-escola na contemporaneidade: fenômeno social/interrogações sociológicas. Análise Social, n. 176, p. 563-578, 2005.

PALERMO, G. A.; SILVA, D. B. do N.; NOVELLINO, M. S. Fatores associados ao desempenho escolar: uma análise da proficiência em matemática dos alunos do $5^{\circ}$ ano do ensino fundamental da rede municipal do Rio de Janeiro. Revista Brasileira de Estudos de População, São Paulo, v. 31, n. 2, p. 367-394, 2014.

PRATTA, E.; SANTOS, M. Família e adolescência: a influência do contexto familiar no desenvolvimento psicológico de seus membros. Psicologia em Estudo, v. 12, n. 2, p. 247-256, 2007.

RAUDENBUSH, S. W.; BRYK, A. S. Hierarchical linear models: applications and data analysis methods. Sage, 2002. 
RESENDE, T.; NOGUEIRA, C.; NOGUEIRA, M. Escolha do estabelecimento de ensino e perfis familiares: uma faceta a mais das desigualdades escolares. Educação \& Sociedade, v. 32, n. 117, p. 953-970, 2011.

RIANI, J.; RIOS-NETO, E. Background familiar versus perfil escolar do município: qual possui maior impacto no resultado educacional dos alunos brasileiros? Revista Brasileira de Estudos de População, v. 25, n. 2, p. 251-269, 2008.

SABOIA, A. L.; COBO, B. MATOS, G. G. Desafios e possibilidades da investigação sobre os novos arranjos familiares e a metodologia para identificação de família no censo 2010. Rio de Janeiro: IBGE, Coordenação de População e Indicadores Sociais, 2012. (Texto para Discussão, n. 39).

TAMURA, K. Modelo logístico multinível: um enfoque em métodos de estimação e predição. Tese (Doutorado em Estatística) - Departamento de Matemática e Estatística, Universidade de São Paulo (USP), São Paulo, 2007.

TOMÁS, M. Reviewing family studies: a brief comment on selected topics. Revista Brasileira de Estudos de População, v. 30, n. 1, p. 171-198, 2013.

TOMÁS, M.; WAJNMAN, S.; CARVALHO, A. Family structure and education achievement: an analysis of young adults in Brazil for 2010. In: XIX ENCONTRO NACIONAL DE ESTUDOS POPULACIONAIS. Anais [...]. São Pedro-SP: Abep, 2014.

XAVIER, F.; ALVES, M. A composição social importa para os efeitos das escolas no ensino fundamental? Estudos em Avaliação Educacional, v. 26, n. 61, p. 216-242, 2015.

WOESSMANN, L. An international look at the single-parent family. Education Next, v. 15, n. 2, 2015.

\section{Sobre as autoras}

Larissa de Eleterio Lima é mestre pela Escola Nacional de Ciências Estatísticas (Ence/IBGE) e bacharel em Estatística pela Universidade Federal Fluminense.

Angelita Alves de Carvalho é doutora em Demografia pelo Centro de Desenvolvimento e Planejamento Regional (Cedeplar), da Universidade Federal de Minas Gerais (UFMG). Pesquisadora em informações geográficas e estatísticas da Escola Nacional de Ciências Estatísticas (Ence/IBGE). Professora permanente do programa de pós-graduação em População, Território e Estatísticas Públicas da Ence/IBGE e do programa de pós-graduação em Economia Doméstica da Universidade Federal de Viçosa (UFV).

Denise Britz do Nascimento Silva é PhD em Estatística. Professora e pesquisadora da Escola Nacional de Ciências Estatísticas (Ence/IBGE).

\section{Endereço para correspondência}

Larissa de Eleterio Lima

Rua Sérgio Vergueiro da Cruz, n. 1, apt. 302, Fonseca

24120-140 - Niterói-RJ, Brasil 


\author{
Angelita Alves de Carvalho \\ R. André Cavalcanti, n. 106, Centro \\ 20231-050 - Rio de Janeiro-RJ, Brasil \\ Denise Britz do Nascimento Silva \\ Rua Campinas, n. 25, Grajaú \\ 20561-250 - Rio de Janeiro-RJ, Brasil
}

\begin{abstract}
Family arrangements and school performance of 5th and 9th year students in Brazil in 2015

Family arrangments have experienced several changes due to dynamic processes, such as reduction of fertility, emancipation of women and their consequent insertion in the labor market, increase in the number of divorces and life expectancy. These changes led to a reduction in the size of families and a diversification of their composition. Given the emergence of new family structures and the changes resulting from social dynamics, this study aimed to analyze the relationship between family arrangements and school performance of $5^{\text {th }}$ and $9^{\text {th }}$ grade students in public schools in Brazil in 2015, with data from Prova Brasil. Math scores were used as a measure of performance and the effects of the family were evaluated using hierarchical modeling of the data. The results showed a small effect of family arrangements on average mathematics proficiency but revealed other elements and mediators related to school results, such as socioeconomic status, student trajectory, individual school habits and the school environment, had a stronger connection with school performance than the composition of the arrangement itself.
\end{abstract}

Keywords: Family arrangements. Scholar outcomes. Hierarchical models.

\title{
Resumen
}

Acuerdos familiares y rendimiento escolar de estudiantes de quinto y noveno año en Brasil en 2015

Los arreglos familiares se han visto transformados por diversos procesos dinámicos como la reducción de la fecundidad, la emancipación de la mujer y su consecuente inserción en el mercado laboral, el aumento del número de divorcios y de la esperanza de vida. Estos cambios llevaron a una disminución del tamaño de las familias y a una diversificación de su composición. Frente, entonces, al surgimiento de nuevas estructuras familiares y a los cambios resultantes de la dinámica social, este estudio tuvo como objetivo analizar la relación de los arreglos familiares con el desempeño escolar de los estudiantes de quinto y noveno grado de las escuelas públicas de Brasil en 2015, a partir de los datos de Prova Brasil. La puntuación de Matemáticas se utilizó como medida de rendimiento y los efectos de la familia se evaluaron mediante un modelo jerárquico de los datos. Los resultados mostraron poco efecto de los arreglos familiares sobre la competencia promedio en Matemáticas y evidenciaron que otros elementos y mediadores relacionados con los resultados escolares, como el nivel socioeconómico, la trayectoria del 
estudiante, los hábitos escolares individuales y el entorno escolar, presentaban una mayor relación con el rendimiento escolar que la composición del arreglo en sí.

Palabras clave: Arreglos familiares. Rendimiento escolar. Modelos jerárquicos.

Recebido para publicação em 21/11/2019

Aceito para publicação em 05/02/2021 